\title{
Structural and Optical Properties of Chemical Bath Deposited Silver Oxide Thin Films: Role of Deposition Time
}

\author{
A. C. Nwanya, ${ }^{1}$ P. E. Ugwuoke, ${ }^{1}$ B. A. Ezekoye, ${ }^{2}$ R. U. Osuji, ${ }^{2}$ and F. I. Ezema ${ }^{2}$ \\ ${ }^{1}$ National Centre for Energy Research and Development, University of Nigeria, Nsukka 41001, Nigeria \\ ${ }^{2}$ Department of Physics and Astronomy, University of Nigeria, Nsukka 41001, Nigeria \\ Correspondence should be addressed to A. C. Nwanya; chinweasum@yahoo.com
}

Received 3 December 2012; Revised 21 March 2013; Accepted 22 March 2013

Academic Editor: Zhimin Liu

Copyright (c) 2013 A. C. Nwanya et al. This is an open access article distributed under the Creative Commons Attribution License, which permits unrestricted use, distribution, and reproduction in any medium, provided the original work is properly cited.

\begin{abstract}
Silver oxide thin films were deposited on glass substrates at a temperature of $50^{\circ} \mathrm{C}$ by chemical bath deposition technique under different deposition times using pure $\mathrm{AgNO}_{3}$ precursor and triethanolamine as the complexing agent. The chemical analysis based on EDX technique shows the presence of $\mathrm{Ag}$ and $\mathrm{O}$ at the appropriate energy levels. The morphological features obtained from SEM showed that the $\mathrm{Ag}_{x} \mathrm{O}$ structures varied as the deposition time changes. The $\mathrm{X}$-ray diffraction showed the peaks of $\mathrm{Ag}_{2} \mathrm{O}$ and $\mathrm{AgO}$ in the structure. The direct band gap and the refractive index increased as the deposition time increased and was in the range of $1.64-1.95 \mathrm{eV}$ and $1.02-2.07$, respectively. The values of the band gap and refractive index obtained indicate possible applications in photovoltaic and photothermal systems.
\end{abstract}

\section{Introduction}

Silver being multivalent forms various phases like $\mathrm{Ag}_{2} \mathrm{O}$, $\mathrm{AgO}, \mathrm{Ag}_{3} \mathrm{O}_{4}, \mathrm{Ag}_{4} \mathrm{O}_{3}$, and $\mathrm{Ag}_{2} \mathrm{O}_{3}$ by interacting with oxygen [1]. These oxides have different crystalline structures leading to a variety of physiochemical, electrochemical, electronic, and optical properties. The most observable and stable phases are $\mathrm{Ag}_{2} \mathrm{O}$ and $\mathrm{AgO}$ [2]. $\mathrm{Ag}_{x} \mathrm{O}$ thin films have been widely studied due to their wide range of applications. The recent interest in silver oxide is for its potential use in optical memories.

Photoactivation of silver oxide leads to nanosilver clusters. These nanoclusters emit fluorescence and also exhibit plasmonic behavior. These properties have a wide application range from ultra high density optical data storage $[3,4]$ to plasmon photonic devices $[5,6]$. They are also used as a sensor for gas detection $[7,8]$ and photovoltaic materials $[9,10]$. Fortiu and Weichman [11] reported that silver oxide is a p-type semiconductor with a band gap of $1.2 \mathrm{eV}$ while other studies have shown that $\operatorname{Ag}_{x} \mathrm{O}$ films have a wide range of energy band gap of between 1.2 and $3.4 \mathrm{eV}$ [12, 13]. This wide range of band gap is as a result of different stoichiometries, crystalline phases, and properties arising from different deposition techniques.
The major routes used for $\operatorname{Ag}_{x} \mathrm{O}$ films deposition are reactive sputtering of silver metal in an oxygen-containing argon atmosphere $[4,12-14]$ and electron-beam evaporation of silver metal $[15,16]$. Another method is the pulsed laser deposition technique $[15,17]$. These methods take place in gaseous phase hence requiring high temperatures. These high temperature methods also limit the type of substrates used to high temperature resistant substrates. Alternatively wet chemistry and electrochemical methods have been used as low temperature methods $[18,19]$. Wet chemistry methods generally require the substrates to be dipped inside the precursor solution for days to form thin film materials at temperatures of up to $200^{\circ} \mathrm{C}$ while electrochemical deposition grows thin film materials on conductive substrate at lower temperatures $\left(<90^{\circ} \mathrm{C}\right)$ and in less time $(<2 \mathrm{~h})[18]$. While most wet chemistry deposition at room temperatures takes a long time to get a good deposit [20,21], electrochemical methods require the use of sacrificial Ag wire as anode and the process of electrodeposition is comparatively complex.

In this work, oxides of silver were deposited on glass substrates by chemical bath deposition method at a temperature of $50^{\circ} \mathrm{C}$ on a hot plate. Chemical bath deposition is the simplest way to deposit thin films of some metal oxides, which are known to have spectrally selective characteristics 


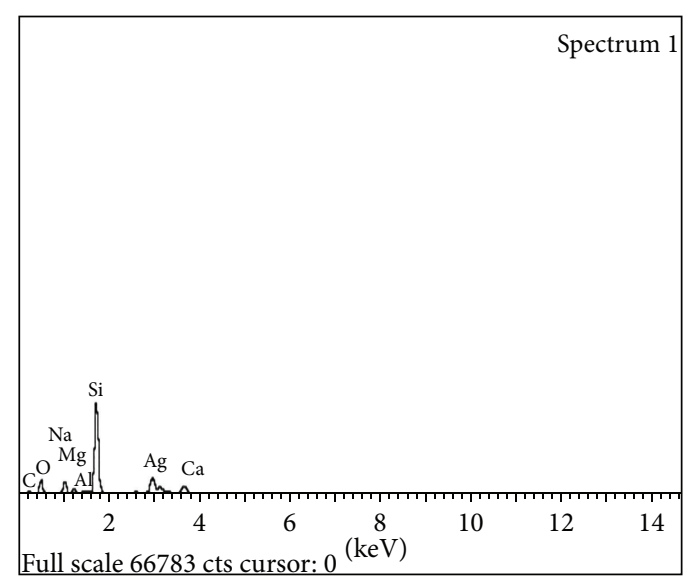

(a)

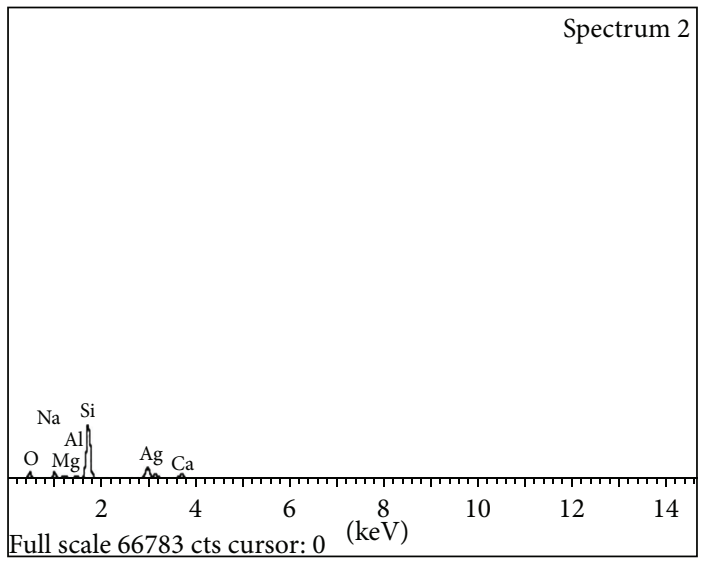

(c)

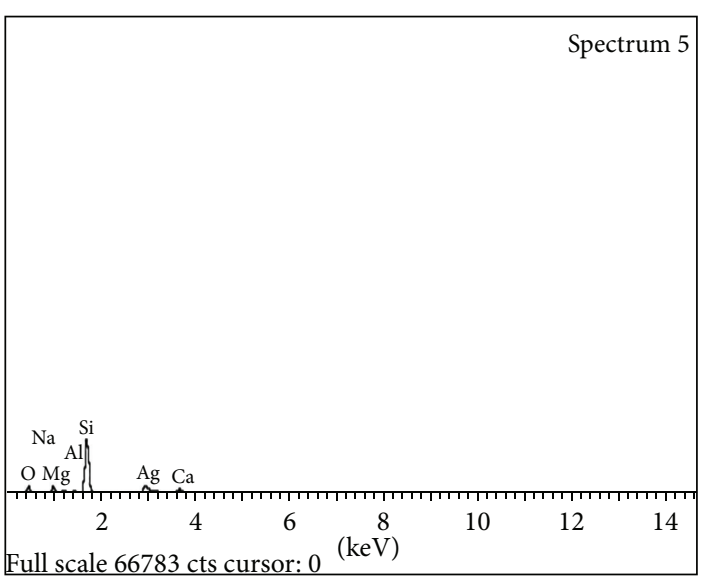

(b)

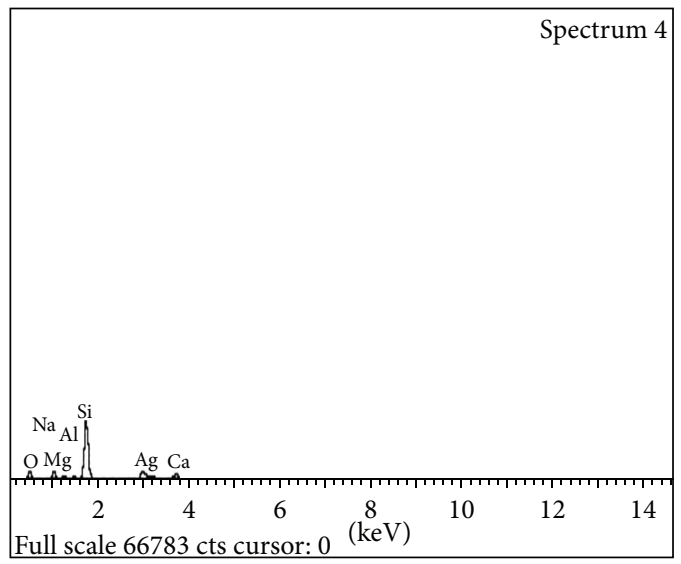

(d)

FIgURE 1: The EDS spectrum of $\operatorname{Ag}_{x} \mathrm{O}$ deposited after (a) 60 mins, (b) 70 mins, (c) 80 mins, and (d) 90 mins.

suitable for photothermal and material applications [19]. The optical, structural, and morphological properties of the deposited film were studied and manipulated by varying the deposition time. The correlation between deposition time and the physical features of $\mathrm{Ag}_{x} \mathrm{O}$ film was illustrated and possible applications based on these features were presented.

\section{Experimental Details}

$0.25 \mathrm{~g}$ of silver nitrate $\left(\mathrm{AgNO}_{3}\right)$ solid was dissolved in $5 \mathrm{~mL}$ of distilled water in a $100 \mathrm{~mL}$ beaker. Then, triethanolamine TEA solution was added dropwise with constant stirring until the initially formed precipitate was dissolved (brownish solution becomes colorless). More distilled water was added to make a total volume of $80 \mathrm{~mL}$. The $\mathrm{pH}$ of the bath was 8.0. Glass slides that have been precleaned by degreasing in concentrated $\mathrm{H}_{2} \mathrm{SO}_{4}$, washed with water and detergent, and rinsed with distilled water were vertically placed into the beaker and the bath was brought to and kept at $50^{\circ} \mathrm{C}$ on a hot plate. After various periods of time $(50,60,70,80$, and 90 mins), the coated slides were removed from the bath, thoroughly rinsed with distilled water, and air-dried using electrical hand drier. The films were annealed at $200^{\circ} \mathrm{C}$ for better adhesion and homogeneity on the substrates.
2.1. Characterizations. The elemental composition of the samples were determined by X-Ray Energy Dispersive spectroscopy (EDS) with accelerating voltage of $20 \mathrm{kV}$ while phase identification was performed by means of $\mathrm{X}$-ray diffraction (XRD) using an XPERT-PRO diffractometer with $\mathrm{Cu} \mathrm{K-} \alpha$ radiation on an operating voltage of $40 \mathrm{kV}$ and current of $40 \mathrm{~mA}$. The morphology and the size of the prepared particles were investigated with scanning electron microscope (SEM), model S-4700, HITACHI with an acceleration voltage of $10 \mathrm{kV}$ and the magnification range from 200X to 5000X. The optical properties of the films were examined by using a UV-Visible spectrophotometer at normal incident of light in the wavelength range of $200-1100 \mathrm{~nm}$. The band gaps and the refractive index of the samples were calculated from the absorption spectra.

\section{Results and Discussion}

3.1. X-Ray Energy Dispersive Spectroscopy (EDS). Figures 1(a), $1(\mathrm{~b}), 1(\mathrm{c})$, and $1(\mathrm{~d})$ show the EDS spectrum of the deposited films. All the EDS spectra show the characteristic X-ray energy level of silver $\left(K_{\alpha}=2.99 \mathrm{KeV}\right.$ and $\left.K_{\beta}=3.10 \mathrm{KeV}\right)$ and oxygen $\left(K_{\alpha}=0.523 \mathrm{KeV}\right)$. 


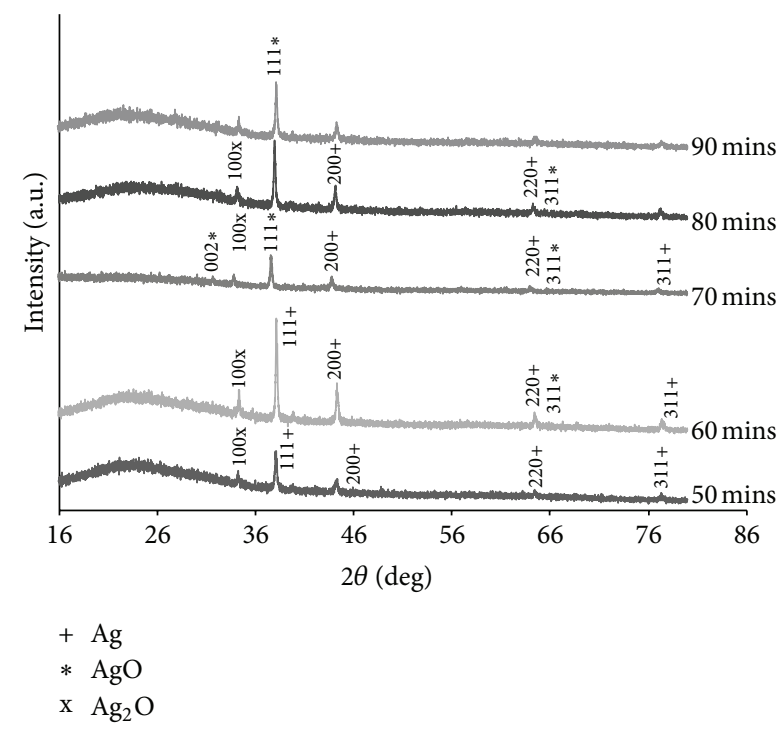

FIGURE 2: The XRD pattern of the deposited $\mathrm{Ag}_{x} \mathrm{O}$ films at different deposition times.

3.2. X-Ray Diffraction. The X-ray diffraction (XRD) pattern of all the films deposited at different deposition times from 50 to 90 mins (Figure 2) shows crystalline nature with planes having cubic orientations (JCPDS 76-1393) [22]. $\mathrm{Ag}_{2} \mathrm{O}$ and $\mathrm{AgO}$ are the dominant oxides present with $\mathrm{Ag}^{+}$nanoparticles dominating at lower deposition time. It is seen that as the deposition time increases, AgO becomes the dominating oxide. This could be attributed to the reaction of $\mathrm{Ag}_{2} \mathrm{O}$ with $\mathrm{OH}^{-}$or the reaction of $\mathrm{Ag}$ with $\mathrm{OH}^{-}$. The possible reactions is shown in (1):

$$
\begin{aligned}
& \mathrm{Ag}_{2} \mathrm{O}+\mathrm{OH} \longrightarrow \mathrm{AgO}+\mathrm{H}_{2} \mathrm{O}+2 \mathrm{e}^{-} \\
& \mathrm{Ag}+\mathrm{OH}^{-} \longrightarrow 2 \mathrm{AgO}+\mathrm{H}_{2} \mathrm{O}+2 \mathrm{e}^{-}
\end{aligned}
$$

At 60 mins deposition time, intense peaks of pure silver (111) are formed (fcc structure) along with (200), (220) peaks of significant intensity. This indicates the dominance of $\mathrm{Ag}$ at this time. Further deposition time showed AgO peaks, (002), (111), and (311). Only (100) peak of $\mathrm{Ag}_{2} \mathrm{O}$ was identified in all the samples.

The crystallite sizes were determined using the wellknown Scherrer equation:

$$
D=\frac{K \lambda}{\beta \cos \theta},
$$

where $K$ is a dimensionless constant often called the shape factor with a value of $0.9, \lambda$ is the wavelength of the $\mathrm{X}$-ray radiation, $\beta$ is the full width at half maximum (FWHM) of the diffraction peak, and $2 \theta$ is the diffraction angle in degrees. The calculated average grain sizes are $10.98 \mathrm{~nm}, 23.88 \mathrm{~nm}$, $14.38 \mathrm{~nm}, 14.10 \mathrm{~nm}, 12.75 \mathrm{~nm}$ for $50,60,70,80$, and $90 \mathrm{mins}$, respectively. Thicknesses of $90.88 \mathrm{~nm}, 100.92 \mathrm{~nm}, 135.75 \mathrm{~nm}$, $143.64 \mathrm{~nm}$ were calculated (Section 3.4) for a deposition times of 50, 70, 80, and 90 mins, respectively (Figure 9). It is observed that the average crystal sizes decreased as the deposition time increased except the 50 min deposited film which was out of trend.
3.3. Scanning Electron Micrography. The surface morphology showed a dominance of Ag nanoclusters at 50 mins deposition time. As the deposition time increases, the crystallite size becomes more defined and shows a mixture of small and big spherical granules (Figure 3). The size of the bigger grains seems to decrease as the deposition time increases. This agrees with the XRD results. The film morphology shows an increase in the thickness of the deposited films as the deposition time increases.

3.4. Optical Studies. Figure 4 shows the absorbance plot as a function of wavelengths as obtained from the UV-VIS spectrophotometer. The transmittance and reflectance were calculated using Beer Lamberts equations [23] and assuming negligible scattering. The films all showed high absorption in the visible region with absorption edges in the blue region of the electromagnetic spectrum. Photoactivation of silver oxides $\mathrm{Ag}_{x} \mathrm{O}$ in this region causes transition from the ground to excited state. The electrons transit to the impurities energy level induced by photocatalytic centers $\left(\mathrm{Ag}_{3} \mathrm{O}, \mathrm{AgO}_{2}+\mathrm{O}\right.$, and $\mathrm{Ag}_{3}+\mathrm{O}$ ) when being photoactivated by blue light [24]. This explains why illumination of silver oxide samples with blue and UV mercury lamp produces fluorescent $\mathrm{Ag}_{x}$ nanoclusters [25]. This phenomenon of $\mathrm{Ag}_{x} \mathrm{O}$ is what makes it suitable for Surface Enhanced Raman Scattering detection (SERS) for chemical and biological molecules [26, 27] and optical data storage [3]. There was a decrease in the absorption as the dip time increased from 70 to 90 mins. This is likely due to an increase in the transmittance and reflection of the film as the dip time increases as shown in Figures 5 and 7. This implies that at a higher dip time, transparent films are obtained which could be used as a transparent conducting oxide (TCO). The films also show high transmittance in the near infrared region and hence could be of use in devices that provide heat and visible light into the house (Figure 6). The observation of peaks in absorption and transmission data is confirmed to be that of the thin film. The film removed after 50 mins showed slight lack of trend with other samples. This is not easily discernible and could have resulted from unforeseen deposition conditions.

The refractive index is related to the reflectance and extinction coefficient according to (3) [28]:

$$
R=\frac{(n-1)^{2}+k^{2}}{(n+1)^{2}+k^{2}},
$$

where $R$ is the reflectance, $k$ is the extinction coefficient, and $n$ is the refractive index of the medium. For semiconductors and insulators in which absorption is high and interference is neglected, $k^{2} \ll n^{2}$, the relationship approximates to

$$
R=\frac{(n-1)^{2}}{(n+1)^{2}}
$$

Chopra and Das [29] and Barik et al. [30] give

$$
n=\frac{(1+R+\sqrt{R})}{(1-R)},
$$




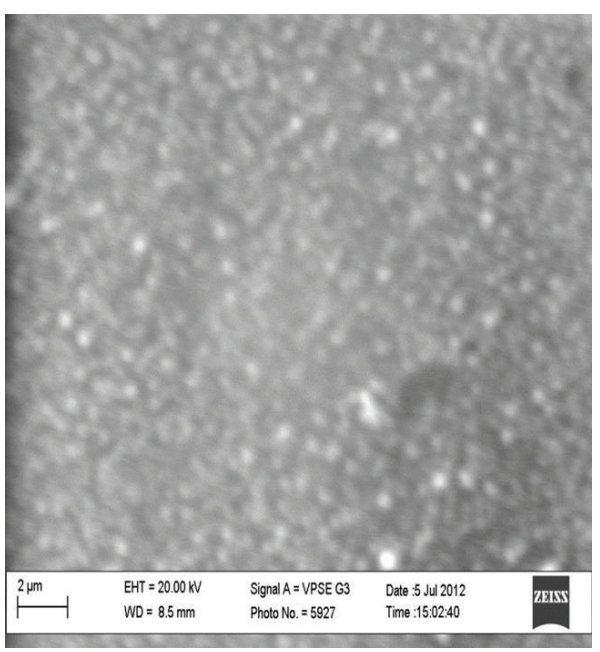

(a)

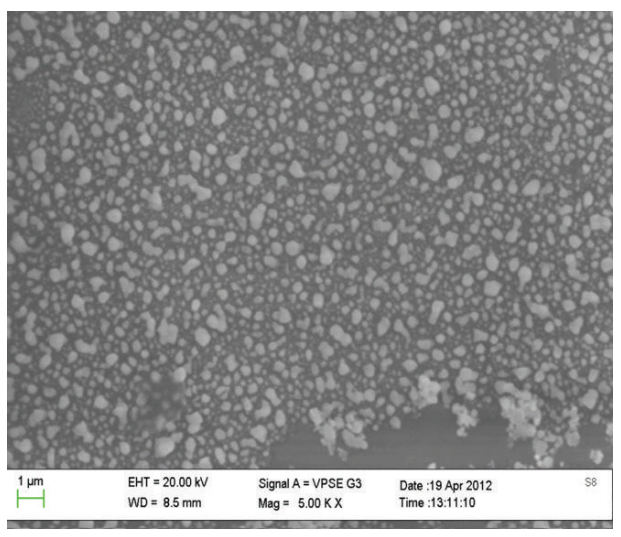

(c)

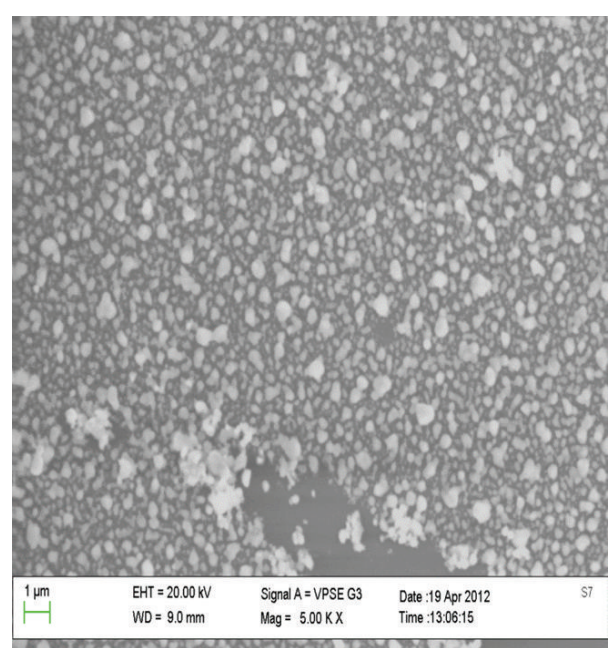

(b)

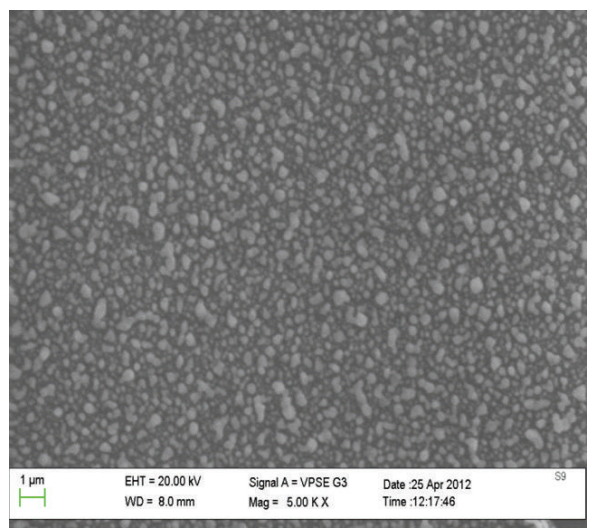

(d)

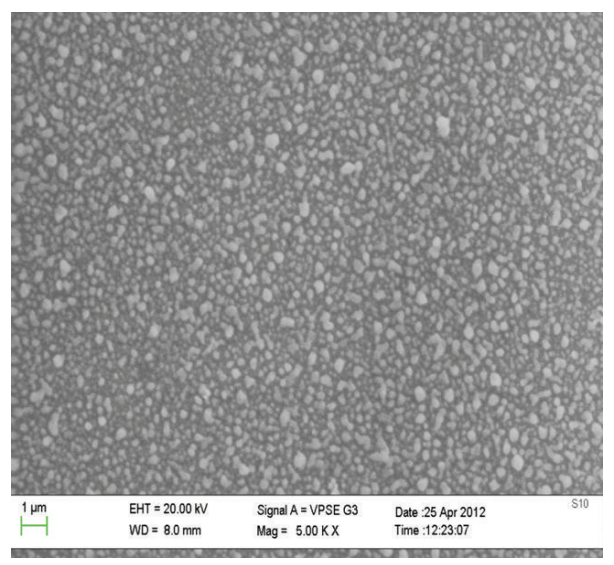

(e)

Figure 3: The SEM images of the deposited films after (a) 50 mins, (b) 60 mins, (c) 70 mins, (d) 80 mins, and (e) 90 mins.

where $n$ is seen to be dependent on $R$ only and can be computed for known values of $R$. Figure 8 shows the plot of index of refraction against photon energy. The range of refractive index was seen to be between 1.02 to 2.07 with increasing trend between the 70 to 90 mins dip time. The 50 mins dip time showed an anomaly. The refractive indices were higher in visible wavelength region and the range of the values indicates possible applications in ultra high density optical nonvolatile memories [5] and also as a transparent conducting oxide. It could also be deduced from the graph that long dip time results in higher refractive index silver oxide film in the visible region making the film a good photovoltaic material. This is because high refractive index implies slower or retarded radiation in the medium, hence 


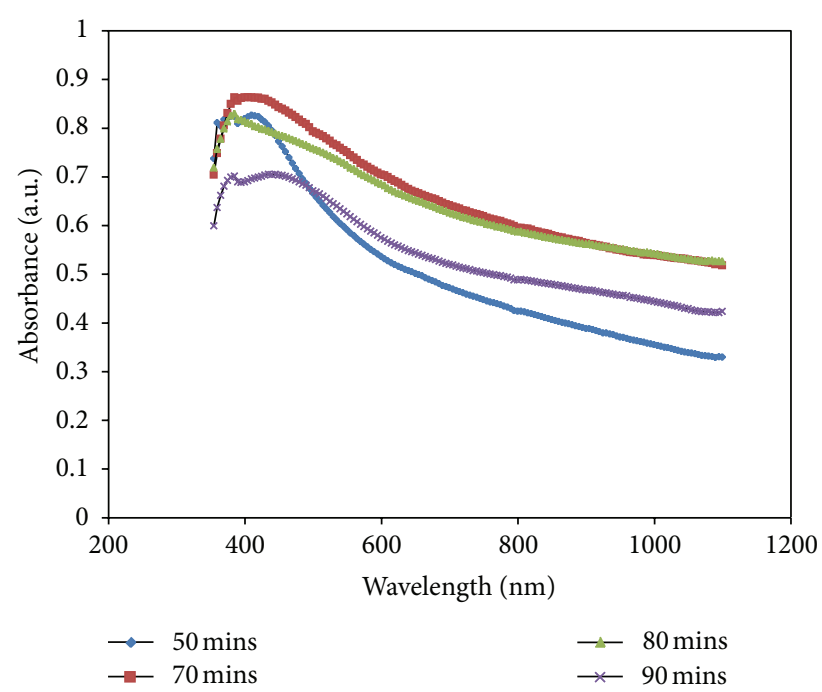

Figure 4: Absorption spectrum of the films.

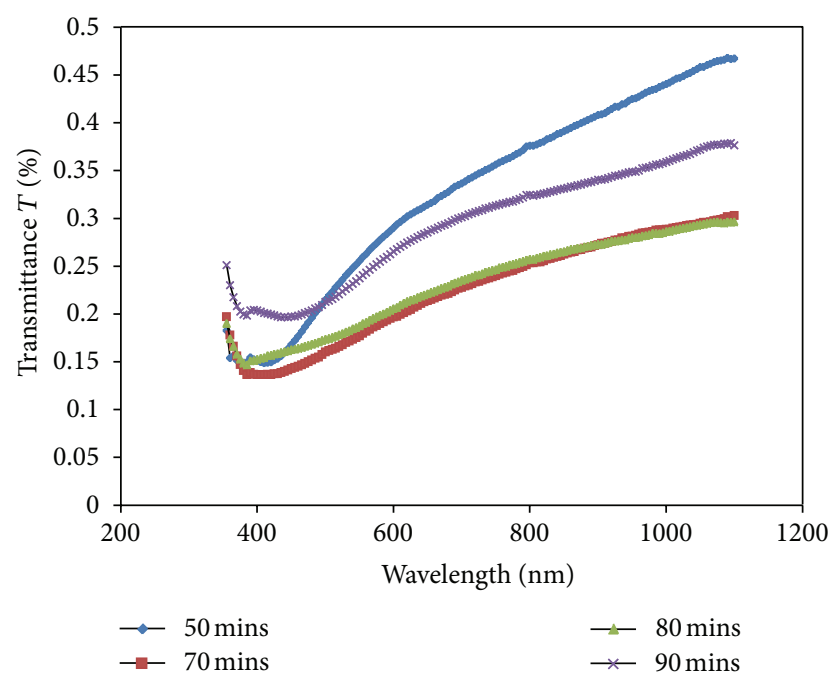

FIGURE 5: Transmittance versus wavelength.

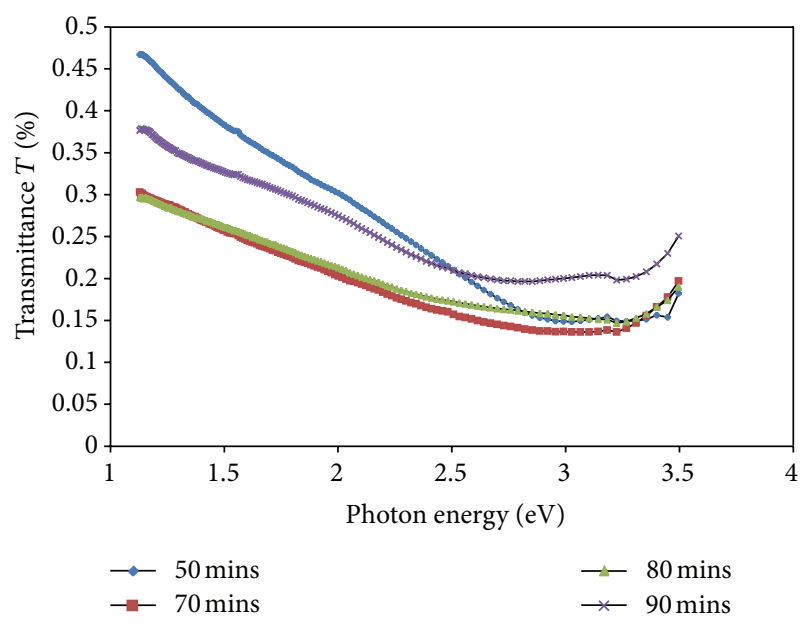

FIgURE 6: Transmittance versus photon energy.

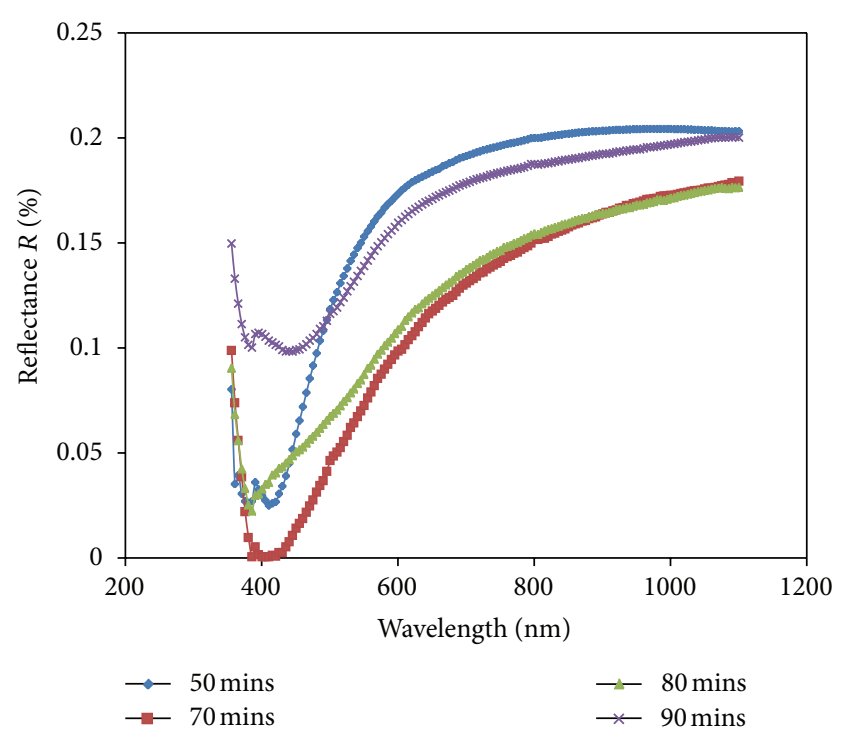

Figure 7: Reflectance versus wavelength.

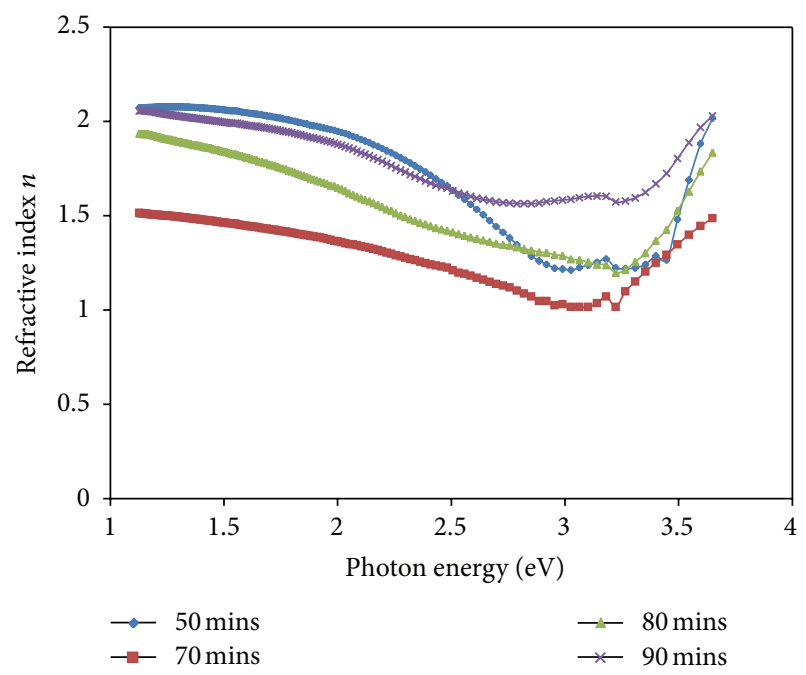

FIgURE 8: Refractive Index $n$ against photon energy.

a longer time to transverse the medium which results in interaction with the electrons leading to possible electron excitation. Data on the refractive index of silver oxide thin films is not reported in most literature (to the extent known to the authors) but Goodman [31] obtained refractive index in the range of 1.186-1.204 for silver oxide films deposited using $\mathrm{dc}$ magnetron sputtering technique.

The thickness of the film was obtained from the transmission spectrum using the envelop method described in the literature [32, 33] and applying (6) as given by Tan et al. [32]:

$$
2 n d=\frac{k \lambda}{2},
$$

where the order $k$ is even for constructive interference and uneven for destructive interference, $d$ is the thickness and $n$ 


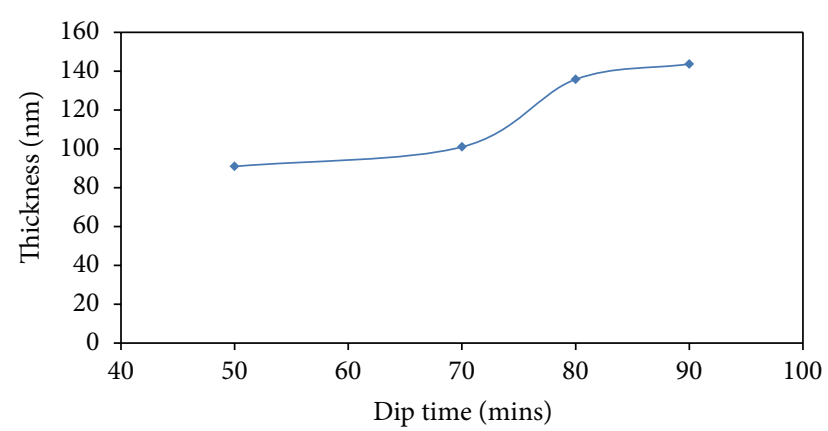

FIgURE 9: Thickness of the deposited film.

is the refractive index. The order was derived by dividing (6) by two successive extrema:

$$
\begin{gathered}
\frac{n\left(\lambda_{k}\right)}{n\left(\lambda_{k+1}\right)}=\frac{k}{k+1} \frac{\lambda_{k}}{\lambda_{k+1}}, \\
k=-\frac{1}{n\left(\lambda_{k}\right) / n\left(\lambda_{k+1}\right)-\lambda_{k} / \lambda_{k+1}} .
\end{gathered}
$$

The values of $k$ were calculated and used to determine the thickness of the films as shown in Figure 8. There was a gradual increase in the film thickness as the dip time increased. Thicknesses of $90.88 \mathrm{~nm}, 100.92 \mathrm{~nm}, 135.75 \mathrm{~nm}$, and $143.64 \mathrm{~nm}$ were calculated for a deposition times of 50 , 70,80 , and 90 mins, respectively. This implied that there was more deposit as the dip time increased as it could be expected.

The absorption coefficient $\alpha$ was calculated using

$$
\alpha=\frac{\ln (1 / T)}{d} .
$$

Figure 10 shows the plot of absorption coefficient as a function of photon energy. It could be seen from the graph that the films had maximum absorptions between 3.0 and $3.2 \mathrm{eV}$.

These absorption spectra, which are the most direct and perhaps the simplest method for probing the band structure of semiconductors, are employed in the determination of the energy gap, $E_{\mathrm{g}}$. The $E_{\mathrm{g}}$ was calculated using the well-known Tauc's relation:

$$
\alpha=A \frac{\left(h v-E_{\mathrm{g}}\right)^{n}}{h v},
$$

where $A$ is a constant, $h \nu$ is the photon energy, and $\alpha$ is the absorption coefficient, while $n$ depends on the nature of the transition. For direct transitions $n=1 / 2$ or $2 / 3$, while for indirect ones $n=2$ or 3 , depending on whether they are allowed or forbidden, respectively. The best fit of the experimental curve to a band gap semiconductor absorption function was obtained for $n=1 / 2$ to obtain direct band gap energy values. The obtained values are $1.95 \mathrm{eV}, 1.64 \mathrm{eV}$, $1.66 \mathrm{eV}$, and $1.70 \mathrm{eV}$ for dip time of $50 \mathrm{~min}, 70 \mathrm{mins}, 80 \mathrm{mins}$, and 90 mins, respectively (Figure 11). There is a slight increase in band gap as the dip times increases. Comparing with what other authors have done, Raju et al. [5] obtained a band

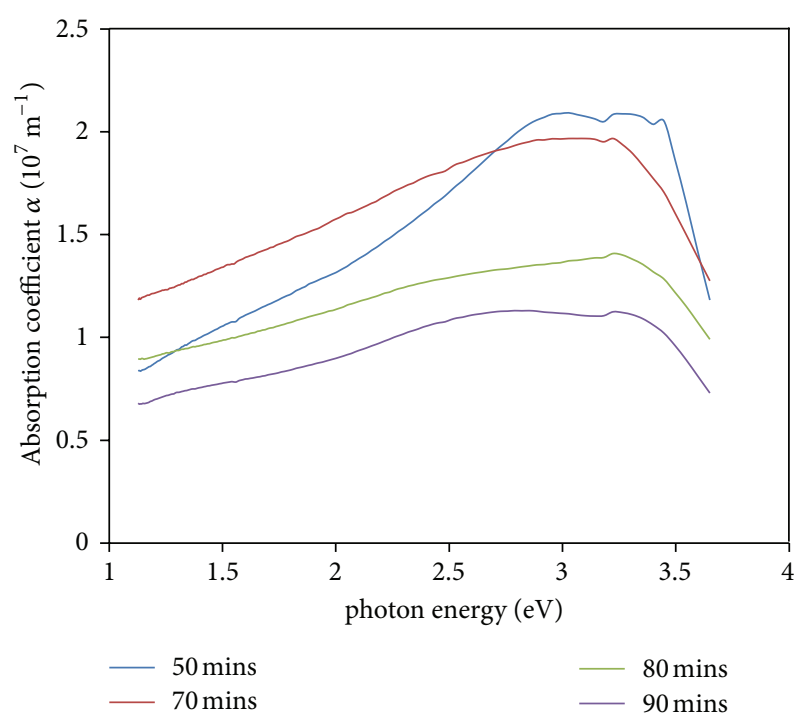

FIgURe 10: Absorption coefficient versus photon energy.

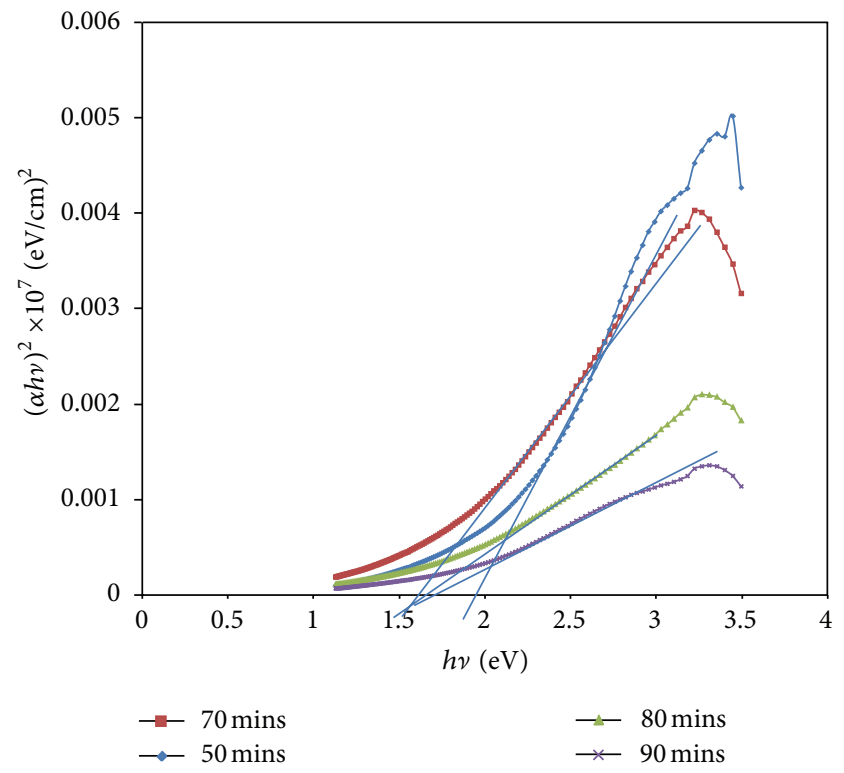

FIGURE 11: Direct band gap plot.

gap in the range of 1.01-0.93 eV and Fortiu and Weichman [11], obtained 1.2 eV while Ramesh et al. [14], obtained $3.5 \mathrm{eV}$. This wide disparity in values as stated before is as a result of different stoichiometries resulting from different deposition techniques.

\section{Conclusion}

The role of deposition time in the silver oxide thin films prepared by chemical bath deposition method has been investigated. Oxides of silver were formed as shown by the X-ray diffraction. AGO dominated at higher dip time. The optical studies show that relatively transparent films in the visible and near infrared regions are formed at higher 
deposition time. This implies that at high dip time TCO (transparent conducting oxide) materials are obtained. The band gap, film thickness, and refractive index increased slightly as the deposition time increased while the crystal size decreased as the deposition time increased. The higher refractive index of samples at high dip time implies that the samples are good material for photovoltaic applications.

\section{References}

[1] M. Bielmann, P. Schwaller, P. Ruffieux, O. Gröning, L. Schlapbach, and P. Gröning, "AgO investigated by photoelectron spectroscopy: evidence for mixed valence," Physical Review B, vol. 65, no. 23, Article ID 235431, 5 pages, 2002.

[2] W. E. Garner and L. W. Reeves, "The thermal decomposition of silver oxide," Transactions of the Faraday Society, vol. 50, pp. 254-260, 1954.

[3] S. M. Hou, M. Ouyang, H. F. Chen et al., "Fractal structure in the silver oxide thin film," Thin Solid Films, vol. 315, no. 1-2, pp. 322-326, 1998.

[4] J. Tominaga, D. Buchel, C. Mihalcea, T. Shime, and T. Fukaya, "The application of silver oxide thin films to plasmon photonic devices," MRS Proceedings, vol. 728, article S7.3, 2002.

[5] N. R. C. Raju, K. J. Kumar, and A. Subrahmanyam, "Physical properties of silver oxide thin films by pulsed laser deposition: effect of oxygen pressure during growth," Journal of Physics D, vol. 42, no. 13, Article ID 135411, 2009.

[6] J. Tominaga, "The application of silver oxide thin films to plasmon photonic devices," Journal of Physics: Condensed Matter, vol. 15, no. 25, p. 1101, 2003.

[7] B. J. Murray, Q. Li, J. T. Newberg, J. C. Hemminger, and R. M. Penner, "Silver oxide microwires: electrodeposition and observation of reversible resistance modulation upon exposure to ammonia vapor," Chemistry of Materials, vol. 17, no. 26, pp. 6611-6618, 2005.

[8] B. J. Murray, J. T. Newberg, E. C. Walter, Q. Li, J. C. Hemminger, and R. M. Penner, "Reversible resistance modulation in mesoscopic silver wires induced by exposure to amine vapor," Analytical Chemistry, vol. 77, no. 16, pp. 5205-5214, 2005.

[9] E. Tselepis and E. Fortin, "Preparation and photovoltaic properties of anodically grown $\mathrm{Ag}_{2} \mathrm{O}$ films," Journal of Materials Science, vol. 21, no. 3, pp. 985-988, 1986.

[10] Y. Ida, S. Watase, T. Shinagawa et al., "Direct electrodeposition of $1.46 \mathrm{eV}$ bandgap silver(I) oxide semiconductor films by electrogenerated acid," Chemistry of Materials, vol. 20, no. 4, pp. 1254-1256, 2008.

[11] E. Fortiu and F. L. Weichman, "Photoconductivity in $\operatorname{Ag}_{2} \mathrm{O}$," Physica Status Solidi A, vol. 5, no. 3, pp. 515-519, 1964.

[12] J. F. Dierson and C. Rousselot, "Stability of reactively sputtered silver oxide films," Surface and Coatings Technology, vol. 200, no. 1-4, pp. 276-279, 2005.

[13] Y. C. Her, Y. C. Lan, W. C. Hsu, and S. Y. Tsai, "Effect of constituent phases of reactively sputtered $\mathrm{AgO}_{x}$ film on recording and readout mechanisms of super-resolution nearfield structure disk," Journal of Applied Physics, vol. 96, no. 3, pp. 1283-1288, 2004.

[14] M. N. V. Ramesh, Y. Sundarayya, and C. S. Sunandana, "Reactively radio frequency sputtered silver oxide thin films: phase evolution and phase stability," Modern Physics Letters B, vol. 21, no. 28, pp. 1933-1944, 2007.
[15] A. A. Schmidt, J. Offermann, and R. Anton, "The role of neutral oxygen radicals in the oxidation of Ag films," Thin Solid Films, vol. 281-282, pp. 105-107, 1996.

[16] S. B. Rivers, G. Bernhardt, M. W. Wright, D. J. Frankel, M. M. Steeves, and R. J. Lad, "Structure, conductivity, and optical absorption of $\mathrm{Ag}_{2-x} \mathrm{O}$ films," Thin Solid Films, vol. 515, no. 24, pp. 8684-8688, 2007.

[17] N. R. C. Raju and K. J. Kumar, "Photodissociation effects on pulsed laser deposited silver oxide thin films: surface-enhanced resonance Raman scattering," Journal of Raman Spectroscopy, vol. 42, no. 7, pp. 1505-1509, 2011.

[18] W. Wei, X. Mao, L. A. Ortiz, and D. R. Sadoway, "Oriented silver oxide nanostructures synthesized through a template-free electrochemical route," Journal of Materials Chemistry, vol. 21, no. 2, pp. 432-438, 2011.

[19] A. J. Varkey and A. F. Fort, "Some optical properties of silver peroxide $(\mathrm{AgO})$ and silver oxide $\left(\mathrm{Ag}_{2} \mathrm{O}\right)$ films produced by chemical-bath deposition," Solar Energy Materials and Solar Cells, vol. 29, no. 3, pp. 253-259, 1993.

[20] Y. Chiu, U. Rambaby, M. H. Hsu, H. P. D. Shieh, C. Y. Chen, and H. H. Lin, "Fabrication and nonlinear optical properties of nanoparticle silver oxide films," Journal of Applied Physics, vol. 94, no. 3, article 1996, 6 pages, 2003.

[21] X. Y. Gao, S. Y. Wang, J. Li et al., "Study of structure and optical properties of silver oxide films by ellipsometry, XRD and XPS methods," Thin Solid Films, vol. 455, pp. 438-442, 2004.

[22] Joint Committee on Powder Diffraction Standards (JCPDS), Powder Diffraction File No. JCPDS 76-1393, International Center for Diffraction Data, Newtown Square, Pa, USA, 2001.

[23] J. D. J. Ingle and S. R. Crouch, Spectrochemical Analysis, Prentice Hall, Upper Saddle River, NJ, USA, 1998.

[24] X. Y. Zhang, X. Y. Pan, Q. F. Zhang et al., "Synthesis of silver oxide nano-scale thin films and photo-activated dynamic luminescence from their nanoparticles," Acta Physico-Chimica Sinica, vol. 19, no. 3, pp. 203-207, 2003.

[25] L. A. Peyser, A. E. Vinson, A. P. Bartko, and R. M. Dickson, "Photoactivated fluorescence from individual silver nanoclusters," Science, vol. 291, no. 5501, pp. 103-106, 2001.

[26] N. R. C. Raju, K. J. Kumar, and A. Subrahmanyam, "Silver oxide (AgO) thin films for surface enhanced Raman scattering (SERS) studies," AIP Conference Proceedings, vol. 1267, pp. 1005-1006, 2010.

[27] L. Zhang, Y. Fang, and P. Wang, "Experimental and DFT theoretical studies of surface enhanced Raman scattering effect on the silver nano arrays modified electrode," Spectrochimica Acta A, vol. 93, pp. 363-366, 2012.

[28] K. L. Chopra and L. K. Malhota, Eds., Optical Properties of Thin Films, Tata McGraw-Hill, New Delhi, India, 1985.

[29] K. L. Chopra and S. R. Das, Thin Film Solar Cells, Plenum Press, New York, NY, USA, 1983.

[30] U. K. Barik, S. Srinivasan, C. L. Nagendra, and A. Subrahmanyam, "Electrical and optical properties of reactive DC magnetron sputtered silver oxide thin films: role of oxygen," Thin Solid Films, vol. 429, no. 1-2, pp. 129-134, 2003.

[31] A. M. Goodman, "Optical interference method for the approximate determination of refractive index and thickness of a transparent layer," Applied Optics, vol. 17, no. 17, pp. 2779-2787, 1978. 
[32] W. C. Tan, K. Koughia, J. Singh, and S. O. Kasap, Optical Properties of Condensed Matter and Applications, edited by J. Singh, John Wiley \& Sons, New York, NY, USA, 2006.

[33] G. Benno and K. Joachim, Optical Properties of Thin Semiconductor Films, 2012, http://home.fnal.gov/ jkopp/tum/pdf/ F/hl_spekt.pdf. 

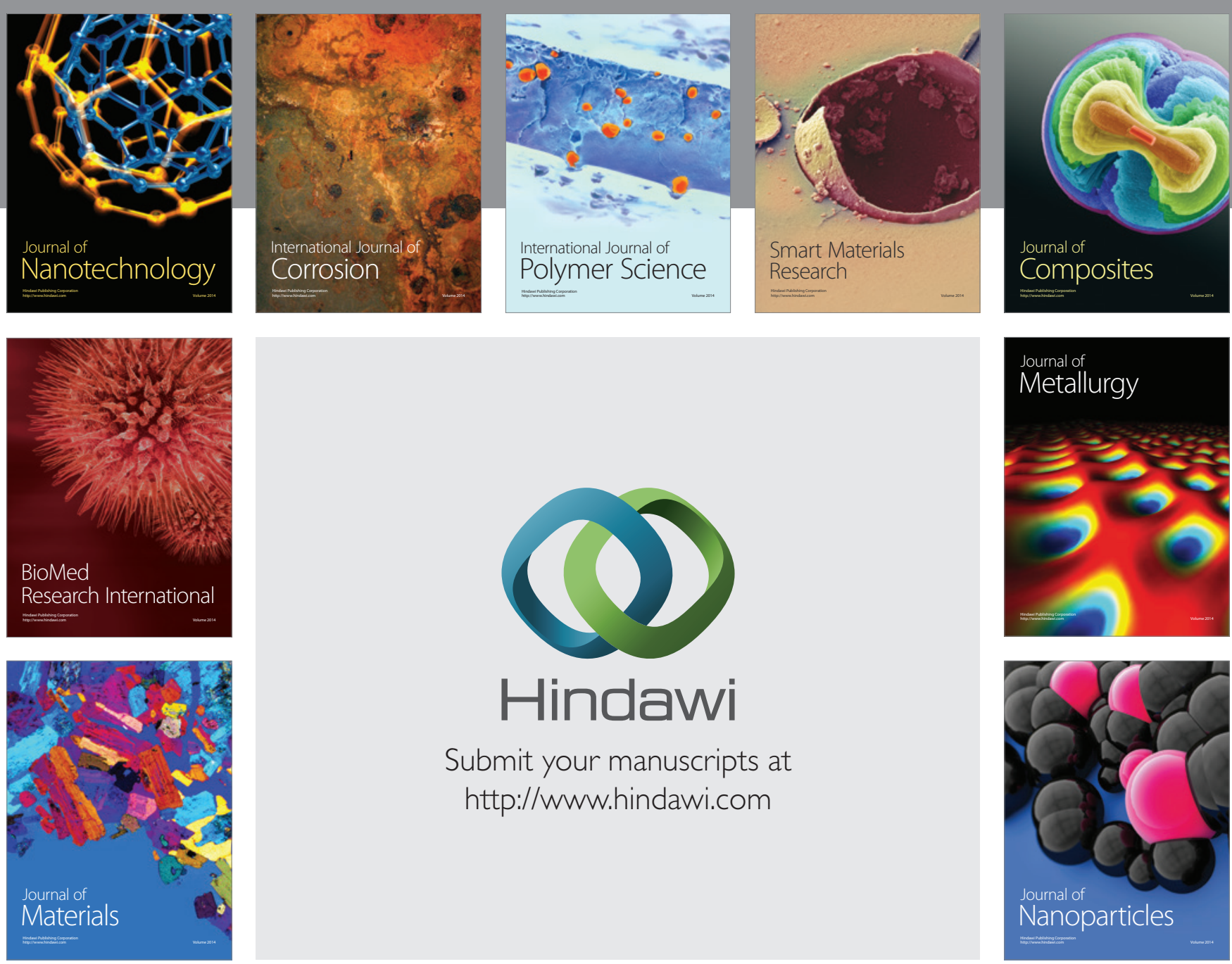

Submit your manuscripts at http://www.hindawi.com
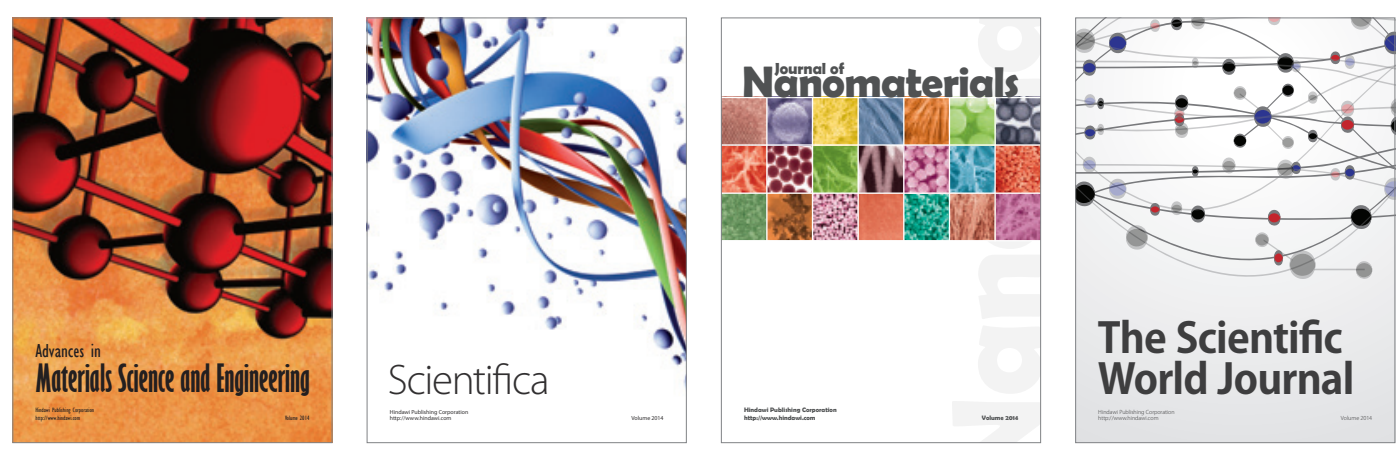

\section{The Scientific World Journal}
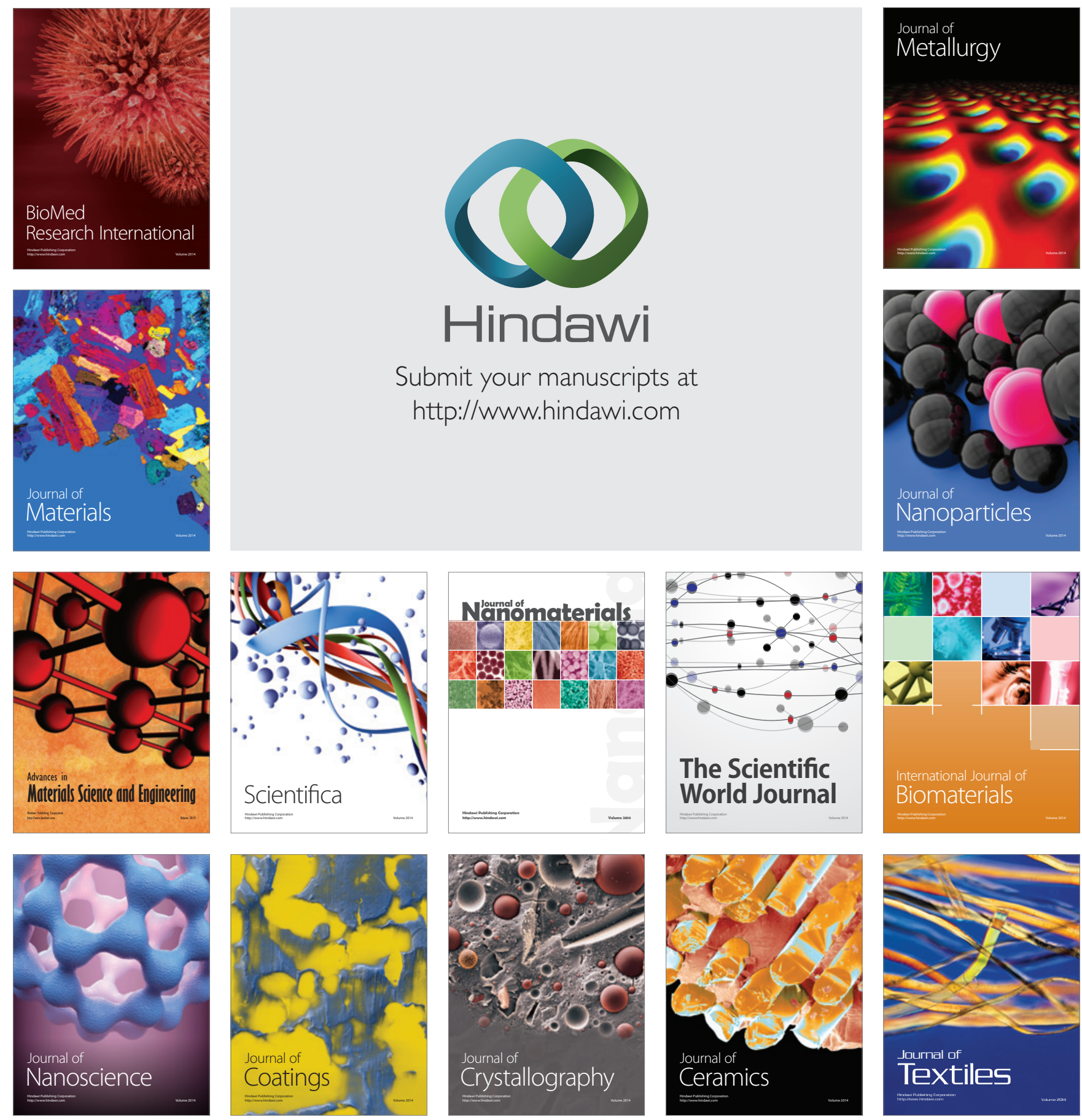